\title{
Ensino como formação técnica e política para o exercício da função social da Arquitetura \\ resgate da experiência de Mayumi Watanabe de Souza Lima em São Carlos ${ }^{1}$
}

\author{
Beatriz Borges Araujo Frota, \\ Aline Coelho Sanches*
}

Resumo Este artigo trata da atuação docente da arquiteta Mayumi Watanabe de Souza Lima (1934-1994), entre 1987 e 1994, no então Curso de Graduação em Arquitetura e Urbanismo da Escola de Engenharia de São Carlos (EESCUSP), hoje Instituto de Arquitetura e Urbanismo de São Carlos (IAU-USP), assunto pouco documentado, mas ainda presente na memória de seus alunos e colegas de profissão. Após o resgate de sua trajetória e seu posicionamento frente ao ensino e produção de arquitetura, aponta-se a indissociabilidade entre sua atuação como arquiteta e como professora, sempre orientada para o projeto de equipamentos de caráter público e social, pensados em rede e a partir da investigação das possibilidades técnicas e de produção da arquitetura.

Palavras-chave: Mayumi Watanabe de Souza Lima, ensino de arquitetura, equipamentos públicos.

\section{La enseñanza como formación técnica y política para el ejercicio de la función social de la Arquitectura: rescate de la experiencia de Mayumi Watanabe de Souza Lima en São Carlos}

\begin{abstract}
Resumen Este artículo trata sobre la actividad docente de la arquitecta Mayumi Watanabe de Souza Lima (1934-1994), entre 1987 y 1994, en particular en el Grado en Arquitectura y Urbanismo de la Escuela de Ingeniería de São Carlos (EESCUSP), hoy día Instituto de Arquitectura y Urbanismo de São Carlos (IAU-USP). En el rescate de su trayectoria y posición ante la enseñanza y la producción arquitectónica, se evidencia una indisociabilidad entre su actuación tanto como arquitecta, como profesora, en aquellos proyectos orientados a equipamientos de carácter público y social, pensados en red y a partir de investigaciones sobre las posibilidades técnicas y la producción arquitectónica.
\end{abstract}

Palabras clave: Mayumi Watanabe de Souza Lima, enseñanza de arquitectura, equipamientos públicos.
Exercising architecture's social role through a technical and political approach to architectural education: a study of Mayumi Watanabe de Souza Lima's experience in São Carlos

Abstract This paper focuses on the work of architect Mayumi
Watanabe de Souza Lima (1934-1994) as a professor at São
Carlos School of Engineering (EESC-USP), during the years
1987 to 1994, in the undergraduate course on Architecture
and Urbanism, now part of São Carlos Institute of Architecture
and Urbanism (IAU-USP). Following an analysis of Mayumi's
career and her views regarding architectural practice and
teaching, the research shows a strong link between her work
as an architect and as a professor, both of which were centered
upon the design of public and community-oriented buildings,
planned as part of a larger network and built through the
exploration of possibilities for different construction techniques.

Keywords: Mayumi Watanabe de Souza Lima, architectural education, public buildings. 
trabalho de Mayumi Watanabe de Souza Lima (1934-1994) como arquiteta esteve sempre ligado à preocupação social. Destacaram-se em sua atuação profissional as investigações e proposições no campo da habitação popular, dos espaços públicos, notadamente aqueles voltados para crianças, e do planejamento de escolas e outros espaços educativos.

Nascida no Japão, Mayumi ${ }^{2}$ migrou ainda criança para o Brasil, onde se naturalizou e, em 1960, formou-se em arquitetura pela Faculdade de Arquitetura e Urbanismo da USP (FAU-USP). Durante sua graduação, de acordo com anotações em seu currículo, atuou como estagiária nos escritórios de Vilanova Artigas (de 1958 a 1960), Joaquim Guedes e Lina Bo Bardi (de 1960 a 1961)³. Sua trajetória profissional, em seguida, foi marcada pela passagem em órgãos públicos. Foi diretora de planejamento do Fundo Estadual de Construções (FECE), de 1966 a 1969; atuou no Centro de Estudos e Pesquisas de Administração Municipal (CEPAM), de 1968 a 1970; trabalhou na Consultoria de Arquitetos e Engenheiros do Programa de Expansão e Melhoria do Ensino (PREMEN), de 1970 a 1979. Entre 1975 e 1979, colaborou com o Centro Brasileiro de Construções Escolares (CEBRACE), e de 1976 a 1978 e, depois de 1983 a 1984, foi Superintendente de Planejamento na Companhia de Construções Escolares do Estado de SP (CONESP). Em 1989, trabalhou na Prefeitura Municipal de São Paulo, durante a gestão de Luiza Erundina, no Departamento de Edificações da Secretaria de Serviços (EDIF), e na coordenação do Centro de Desenvolvimento de Equipamentos Coletivos (CEDEC)/EMURB, de 1990 a 1992 (LIMA, 1995).

De forma entrelaçada a esta atuação, Mayumi construiu uma carreira acadêmica e docente, na qual o ensino da Arquitetura foi exercido dentro de um entendimento amplo da educação, reconhecida enquanto processo de formação política, em constante reflexão sobre a configuração dos espaços educativos e a forma como se estruturava o ensino básico e superior no Brasil. Dois anos após o término da graduação, em 1962, Mayumi se dirigiu para a nova capital, onde realizou seu mestrado e teve sua primeira experiência como professora na Universidade de Brasília (UnB), interrompida em função dos ataques dirigidos à Universidade pelo governo militar (LIMA in PINTO, 1989; BUITONI, 2009; ALIAGA, 2017). Este momento inaugural na docência foi seguido pela experiência na Faculdade de Arquitetura e Urbanismo de Santos (FAU-Santos), entre 1970 e 1971, e na Faculdade de Arquitetura e Urbanismo de São José dos Campos

* Beatriz Borges Araujo Frota é Arquiteta e Urbanista, Instituto de Arquitetura e Urbanismo da Universidade de São Paulo, ORCID <https://orcid.org/00000001-8269-3442>. Aline Coelho Sanches é Arquiteta e Urbanista, Professora do Instituto de Arquitetura e Urbanismo da Universidade de São Paulo, ORCID $<$ https://orcid.org/0000-00016458-0938> (FAU-SJC), entre 1972 a 1974, curso inovador que dava continuidade aos trabalhos de Brasília. Um terceiro momento no ensino foi assinalado pela atuação como professora do então Curso de Graduação em Arquitetura e Urbanismo da Escola de Engenharia de São Carlos da Universidade de São Paulo (EESC-USP), hoje Instituto de Arquitetura e Urbanismo de São Carlos da Universidade de São Paulo (IAU-USP), no período de 1987 a 1994. É desse último momento e dessa experiência particular que este artigo irá tratar.

Apesar do interesse crescente, ainda são poucos os estudos sobre a obra e a atuação de Mayumi. A dissertação de Cássia Schroeder Buitoni (2009), defendida na FAU-USP, 
1 Pesquisa de Iniciação Científica financiada pelo PIBIC/CNPq, desenvolvida e orientada pelos autores.

2 Optamos por denominar a arquiteta de Mayumi ao longo do texto e não Souza Lima, observando a maneira como ela vem sendo conhecida e divulgada pela historiografia no Brasil, assim como ocorrera como Lina Bo Bardi.

3 Buitoni (2009) reporta a data do estágio entre 1959-1961. Tanto o currículo de Mayumi quanto o trabalho de Buitoni dão a entender que o trabalho dos dois arquitetos eram conjuntos nesse momento, que coincide com o período em que Lina se divide entre São Paulo e Salvador.

4São alguns deles: Mayumi Souza Lima. Coletivo Arquitetas Invisíveis, 2015. Disponível em: $<$ https://www.arquitetasinvisiveis.com/mayumi-souza-lima>; Mulheres na arquitetura: a importância de Mayumi Souza Lima. Revista Casa Cláudia, Julho de 2017. Disponível em: <https:// casaclaudia.abril.com. br/arquitetura/mulheres-na-arquitetura-a-importancia-de-mayumi-souza-lima/>; Mayumi Watanabe de Souza Lima: 1934-1994. Grupo Un dia, Uma Arquitecta, Junho de 2015. Disponível em: <https://undiaunaarquitecta.wordpress.com/2015/06/28/ mayumi-watanabe-de-souza-lima-1934-1994/>. Acessos em: 16/08/2019. foi pioneira na abordagem da trajetória da arquiteta, através de uma ampla pesquisa documental. Para além de apresentar um histórico da formação e da sua carreira, Buitoni dedicou especial atenção para as experiências de projeto participativas coordenadas por Mayumi através da CONESP e para o trabalho desenvolvido no CEDEC para a prefeitura de São Paulo. As importantes pesquisas de Maribel Aliaga (2013; 2015; 2017), interessada nos primeiros mestrados defendidos na UnB, levantaram dados e reflexões sobre o período em que Mayumi esteve em Brasília, tanto sobre sua atuação no ensino quanto sobre seu mestrado orientado por João Filgueiras Lima, o Lelé. Já Joana Mello (2017), ocupou-se, assim como Buitoni, da reconstrução da trajetória da arquiteta, ainda que nos limites de um artigo e com menor uso das fontes arquivísticas, mas sua leitura refinada ofereceu um interessante enquadramento do trabalho de Mayumi dentro do panorama da Arquitetura Moderna Brasileira. Os interesses pela obra da arquiteta fazem parte dos esforços de revisão da Arquitetura recente no Brasil, ainda pouco estudada, de reconstrução da história do ensino da disciplina e da recuperação de personagens femininas que foram deixadas de lado pela historiografia. Neste último sentido, multiplicaram-se recentemente, textos curtos de difusão de sua trajetória, inclusive em meios não especializados ${ }^{4}$, que deram maior visibilidade a sua contribuição para o campo da Arquitetura e da cultura do país.

Os interesses acima mencionados também moveram a construção deste estudo, mas seu principal objetivo foi recuperar parte da história de Mayumi, segundo um aspecto pouco aprofundado pelos trabalhos citados anteriormente, reconstruindo sua atuação no Curso de Arquitetura e Urbanismo da EESC-USP (CAU-EESC-USP), em São Carlos. Esta experiência docente, realizada em um momento maduro da sua jornada como educadora e como arquiteta, foi profundamente ligada às pesquisas sobre a préfabricação feita pelos engenheiros da mesma Escola e com o seu próprio trabalho na Prefeitura de São Paulo, quando a redemocratização do país e as lutas populares que ganharam força com a abertura política tiveram influência direta nas suas ações. A contribuição de Mayumi para um curso ainda em seus momentos iniciais, fundada na formação de uma consciência social entre os alunos, foi de grande importância para sua estruturação e para o aprendizado daqueles que com ela conviveram. Quando iniciamos esta pesquisa, em 2016, este curso há pouco completara trinta anos de existência e cinco enquanto Instituto separado da Escola de Engenharia. Observamos, então, a dificuldade de encontrar, nos seus acervos, assim como naqueles da EESC, materiais referentes à arquiteta, ressaltando a necessidade de documentar uma experiência que ainda se encontra na memória daqueles que foram seus alunos e colegas de profissão. Acumulavam-se naquele momento as perguntas sobre qual foi a natureza, o impacto e a herança do ensino de Mayumi no IAU. As respostas que construímos, pouco a pouco com esta pesquisa, mostraram o quanto seu pensamento e sua atuação ainda são ricos de reflexões e caminhos para problemas atuais da Arquitetura e do Urbanismo e do seu ensino.

\section{Ensinar para a função social e ensinar como forma de afinar uma posição sobre a Arquitetura}

Este trabalho foi construído com base nos métodos da pesquisa histórica em arquitetura, depositando grande valor na consulta das fontes primárias e realização de entrevistas, além da consulta de fontes secundárias. Como passo inicial para investigação da atuação docente de Mayumi em São Carlos, sua trajetória foi estudada, examinando 
${ }^{5}$ Agradecemos a indicação dessa fonte por Carlos Roberto Monteiro de Andrade.

${ }^{6}$ As entrevistas e depoimentos que contribuíram para este trabaIho incluem aqueles dos professores Renato Anelli (30/03/2017); Paulo Castral (05/04/2017 - ex -aluno); Carlos Roberto Monteiro de Andrade (26/04/2017); Carlos Martins (ao longo de 2017); Marcelo Tramontano (30/05/2017); Ana Lúcia Cerávolo (19/07/2017 - ex-aluna); Fernando de Mello Franco (31/07/2017) e José Fabrício Ferreira (11 e 30/06/2020 - ex-aluno).

7 Estão coordenando este trabaIho o prof. Jefferson Tavares e a servidora técnico-administrativa Debora Martinez. seu posicionamento com relação a questões da própria arquitetura e de seu ensino, entrelaçada ao contexto social e arquitetônico em que se inseriam. Em um primeiro momento, a atenção foi voltada para a bibliografia sobre Mayumi, através da pesquisa, seleção e leitura de fontes secundárias. Em um segundo momento foi lida a bibliografia de sua autoria, localizada em fontes primárias publicadas, isto é, textos ligados a sua produção acadêmica, entrevistas concedidas por ela e apostilas formuladas para apoio didático da escola de São Carlos, hoje localizadas nas bibliotecas do Campus. A necessidade de contextualização desta experiência de ensino, levou a busca por informações sobre o curso de Arquitetura e Urbanismo da USP em São Carlos, o quadro geral do ensino de arquitetura e o contexto de produção arquitetônica no Brasil nos anos de sua atuação naquela escola.

Entre as fontes primárias, foram consultados os acervos pessoais da arquiteta e de outros professores do curso. Aquele de Mayumi, em conjunto com o de Sérgio de Souza Lima, foi doado por seu filho Mário Watanabe de Souza Lima para a Fundação Perseu Abramo, encontrando-se atualmente no Centro de Memória Sérgio Buarque de Holanda, em São Paulo. A visita à Fundação Perseu Abramo e o contanto com o acervo proporcionou a descoberta de documentos pessoais e institucionais relevantes sobre a passagem de Mayumi na EESC-USP, incluindo programas de disciplinas, anotações de aula, propostas de exercícios, projetos de pesquisa, registro de palestras e outros textos de caráter docente, produzidos em São Carlos e nos outros cursos em que lecionou. Uma dificuldade encontrada nesta etapa foi a impossibilidade de encontrar documentos relevantes para a pesquisa tanto na biblioteca do Instituto de Arquitetura e Urbanismo (IAU-USP) quanto na biblioteca da Escola de Engenharia de São Carlos (EESC-USP), que abrigavam apenas programas resumidos das disciplinas, com informações gerais que também aparecem nos documentos do acervo pessoal de Mayumi. Foi consultado, ainda, o dossiê sobre a arquiteta no quadro da Comissão da Verdade da USP ${ }^{5}$.

Com o intuito de resgatar a memória não-documentada da passagem de Mayumi Souza Lima pelo curso da USP São Carlos, os depoimentos de ex-alunos e professores ajudaram na descoberta de uma imagem de Mayumi além daquela registrada nas fontes citadas, ligada diretamente à memória do curso e daqueles que conviveram com ela ${ }^{6}$. A entrevista com seus ex-alunos possibilitou o resgate de sua figura enquanto professora, sua relação com os estudantes, a dinâmica de suas aulas, as ideias de arquitetura que apoiava e as que se opunha, a forma como a relação entre política e arquitetura era por ela apresentada e a integração da disciplina de projeto com outras áreas. Os depoimentos dos seus colegas professores, por sua vez, foram importantes para a apreensão da contribuição trazida por Mayumi, seu envolvimento na estruturação do curso e da disciplina de Projeto que lecionava, a forma como se dava o convívio profissional com ela, sua visão com relação ao ensino de arquitetura e seu envolvimento com questões políticas.

As atas de reuniões realizadas ao longo do curso não foram diretamente consultadas por nós. Estão, atualmente, em processo de leitura e organização por Debora Martinez para o projeto Memória do IAU-USP ${ }^{7}$ que generosamente compartilhou seus achados conosco.

O estudo de todo este material permitiu-nos construir uma hipótese de que a contribuição de Mayumi foi marcante para o IAU, em especial quanto à ideia de 
formar para o exercício da função social do arquiteto, entendendo o ensino como formação técnica e política, focada na promoção de equipamentos públicos e das relações entre arquitetura e tecnologia, sendo ainda perceptível na escola, mesmo que de forma diluída em disciplinas de projeto. Inversamente, sua atividade como professora em São Carlos e o contato com seus interlocutores ajudou a afinar sua própria visão de arquitetura.

\section{Trajetória docente anterior a São Carlos e seu tempo}

Para entender a natureza do trabalho de Mayumi no CAU-EESC-USP é preciso, inicialmente, observar que a sua trajetória foi marcada por atividades que impactaram em sua atuação no ensino. Com base no currículo organizado pela própria arquiteta, em 1993, Buitoni (2009, p.18) reconhece três eixos em sua atuação profissional: o ensino de Arquitetura, as atividades de projeto e de planejamento para a construção de equipamentos públicos e a produção teórica. A autora ressalta, no entanto, a interrelação entre essas três áreas. Teoria e prática se mostraram fortemente vinculadas no trabalho de Mayumi, motivo pelo qual a busca por um entendimento completo de sua atividade docente não pode deixar de abranger, ainda que brevemente, as outras áreas de atuação. Além disso, é preciso entender o quanto seu trabalho está entrelaçado com o contexto político-econômico-social e com seus interlocutores culturais no campo da Arquitetura. Nos próximos trechos serão descritos e analisados estes dois aspectos para, então, ser realizada a caracterização do trabalho de Mayumi em São Carlos.

A carreira docente de Mayumi se iniciou na Universidade de Brasília (UnB), onde atuou como professora assistente nas disciplinas Teoria da Edificação e Conforto Ambiental, entre 1963 e 1965. Sua ida à Brasília, no ano anterior, foi motivada pela realização de seu mestrado Aspectos da habitação urbana - projeto de habitação para a unidade de vizinhança São Miguel, orientado por Lelé e concluído em 1965. Em sua dissertação, abordou a produção de habitações coletivas no Brasil, com enfoque no projeto habitacional realizado por Mayumi e por seu marido Sérgio de Souza Lima na Asa Norte do Plano Piloto, com a utilização de elementos pré-moldados de concreto armado (ALIAGA, 2017).

Durante o tempo que permaneceu em Brasília, Mayumi teve contato com as experiências de pré-fabricação de Lelé e Niemeyer na UnB, tendo trabalhado no CEPLAN (Centro de Planejamento da UnB). Tal fato, combinado à ênfase dada aos processos construtivos e à experiência dentro do canteiro de obras como atividade dos estudantes no curso de arquitetura da UnB, influenciou em questões que podem ser observadas durante toda a docência de Mayumi e em algumas atividades profissionais, como a coordenação da fábrica de elementos construtivos pré-fabricados do CEDEC/EMURB no início dos anos 1990 .

A experiência na UnB foi de grande importância para Mayumi e Sérgio. Em entrevista conjunta concedida para fomentar a tese de doutorado de seu colega do CAU-EESC, Gelson Pinto, intitulada Prática do projeto no ensino de arquitetura: investigação sobre algumas experiências - São Paulo - 1958/1985, de 1989, foi relatado o caráter inovador do curso de arquitetura da UnB e a influência exercida por ele nos novos cursos de Arquitetura e Urbanismo criados no estado de São Paulo nas décadas seguintes, alguns dos quais tiveram a participação de Mayumi. 
Um desses cursos foi o da FAU-Santos, segunda experiência docente de Mayumi Souza Lima, em que atuou pelo curto período de 1970 a 1971, lecionando a disciplina Tecnologia das Edificações. Além de Mayumi como coordenadora, o departamento de tecnologia tinha como professores Sérgio Souza Lima e Rodrigo Lefèvre, enquanto Sérgio Ferro e o sociólogo Francisco de Oliveira atuavam no departamento de Teoria e História do recém-criado curso. Sua proposta inovadora estava ligada à aproximação dos arquitetos com as camadas populares, conforme explicitado por Sérgio Ferro:

"Propúnhamos um ensino ancorado em questões atuais de uma arquitetura socialmente engajada. Tomamos, por exemplo, uma favela próxima como objeto de estudo de todas as matérias do $1^{\circ}$ ano. Sérgio e Mayumi eram professores de Estrutura, e todos os conceitos básicos dessa matéria surgiam e eram desenvolvidos a partir do estudo das casas da favela. A introdução à Teoria da Arquitetura partia de uma análise socioeconômica da favela, de enquetes sociológicas precisas, de suas condições de produção e da forma resultante, etc. Enfim, todas as matérias tomavam como suporte uma realidade presente, e construíam seus conceitos a partir dela, inclusive, evidentemente, o Projeto. " (FERRO, Sérgio. Depoimento a BUITONI, 2009, p.28)

Na entrevista a Pinto (1989, p.144), Mayumi ressaltava a importância da experiência dos alunos do primeiro ano com a arquitetura das favelas e da busca por abordar a realidade da cidade no curso. Discorria, ainda, sobre a positiva integração entre as áreas de Teoria e Tecnologia, embora a área de Projeto fosse mais isolada. O depoimento concluía que a experiência da FAU-Santos fora breve, e menos bem desenvolvida do que a de São José dos Campos, que se seguiria na carreira docente da arquiteta.

A Faculdade de Arquitetura e Urbanismo de São José dos Campos (FAU-SJC), em que Mayumi atuou de 1972 a 1974, foi outro curso de proposta inovadora, contando ainda com a presença de diversos professores vindos da FAU-Santos. Em São José do Campos, a influência da UnB se fazia mais marcante através da proposta de organização no sistema de ateliers integrados. O modelo, no entanto, enfrentou grandes dificuldades de aplicação prática, sendo substituído dois anos após sua fundação pelo sistema de Unidades Interdepartamentais de Ensino e Pesquisa (UIDs), em um processo coordenado por Mayumi e registrado no texto $O$ surgimento de novas escolas, documento dos alunos e professores da FAU-SJC apresentado no Encontro Nacional Sobre Ensino de Arquitetura, em 1976.

Ainda sobre o curso de São José do Campos, em depoimento à matéria Espaço da Utopia, de Lívia Álvares Pedreira, publicado na revista Arquitetura e Urbanismo n. 5, em abril de 1986, no contexto das divergências existentes no curso, Mayumi enfatizou o consenso com relação a "uma formação mais ampla do arquiteto" e a importância de situar os alunos nas questões regionais e locais, buscando priorizar, assim, não questões teóricas, mas o aprendizado vinculado à experiência de cada indivíduo (figura 1).

8 Em complemento às informações contidas no Relatório Final da Comissão da Verdade, consultamos no Arquivo Geral da USP o processo RUSP 77.1.38124.1.5, referente ao contrato docente de Mayumi Watanabe Souza Lima.
Em 1977, Mayumi foi aprovada pelo Conselho do Departamento de Projeto da FAUUSP para o cargo de auxiliar de ensino, mas jamais chegou a ser contratada devido ao controle ideológico exercido sobre a Universidade durante a Ditadura Militar. A tentativa de contratação e as atas de processos referentes estão relatadas no Relatório Final da Comissão da Verdade da USP, divulgado em 2018 pela instituição ${ }^{8}$. Mayumi 


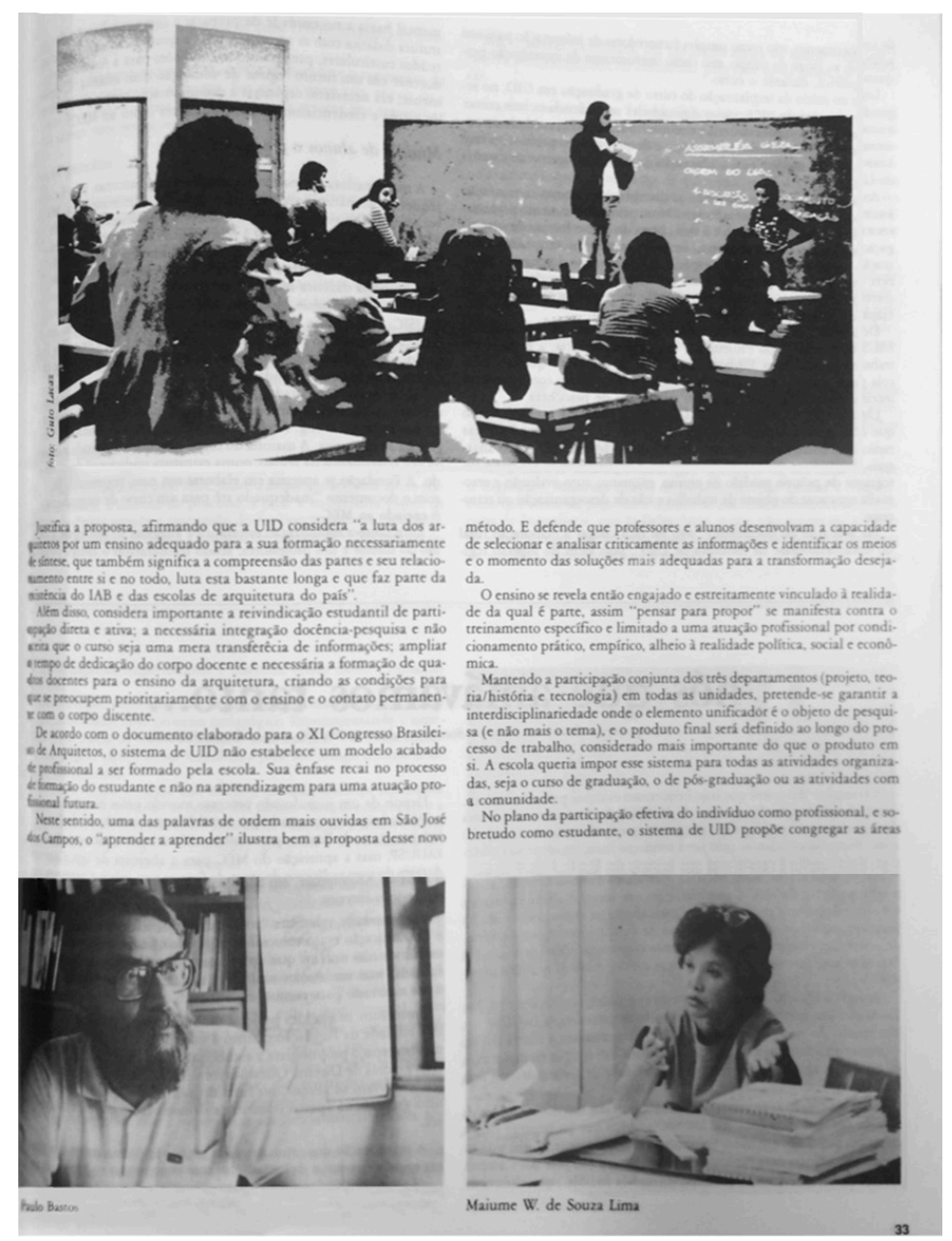

Figura 1: Entrevista de Mayumi para a matéria Espaço da Utopia, sobre o curso da FAU-SJC. Fonte: Página inteira da Revista Arquitetura e Urbanismo, n. 5, abr/1986, p. 33. Acervo da Biblioteca Central da EESC-USP. e Sérgio de Souza Lima tiveram suas acumulações de cargos consideradas regulares e aprovadas pelas empresas em que trabalhavam - CONESP e Empresa Metropolitana da Grande São Paulo (EMPLASA), respectivamente -, bem como manifestação favorável às suas contratações pela FAU-USP. Seus processos, entretanto, não correram de forma regular e foram posteriormente arquivados sem qualquer justificativa.

Mayumi retornou à USP, em 1984, para realizar sua Tese de Doutorado, que jamais chegou a concluir. Desenvolvida na Faculdade de Educação sob orientação do professor Celso de Rui Beisiegel, tratava da produção de equipamentos públicos para a educação, contendo questionamentos a respeito da atuação do Estado nesse processo. Parte do texto de qualificação, intitulado Estado e movimentos populares na construção do prédio escolar: confronto ou colaboração?, foi publicada posteriormente no livro Arquitetura e Educação.

A postura crítica e o posicionamento político de Mayumi são indissociáveis da sua trajetória. Reflexões sobre a atuação do Estado na produção de equipamentos públicos e as políticas educacionais que pouco levavam em conta as experiências infantis podem ser encontradas em seu envolvimento em qualquer de suas áreas de atuação. Essas posições só podem ser entendidas como parte do contexto político, social e econômico em que 
estavam inseridas: a conturbada situação política nacional esteve fortemente ligada aos anos de sua formação e maior parte de sua trajetória profissional. Mayumi esteve envolvida na luta política, por via da atuação no Partido Comunista, movimentos de resistência à ditadura militar e em gestões de esquerda no momento de redemocratização.

Outro apontamento importante para contextualização da produção de Mayumi no quadro arquitetônico brasileiro é sua aproximação e de seu marido Sérgio com o grupo Arquitetura Nova, nome dado posteriormente aos arquitetos Flávio Império, Rodrigo Lefèvre e Sérgio Ferro, tanto nas experiências de ensino de arquitetura e militância política como em suas concepções arquitetônicas.

A busca por uma arquitetura que se aproximava da população e do canteiro, preocupada com as técnicas construtivas para além do interesse na forma, foi uma questão fundamental no trabalho de Mayumi como arquiteta e como professora de projeto. Um exemplo dessa preocupação pode ser encontrado no esforço para comunicação com a comunidades na realização das obras e para formação política dos funcionários da fábrica na CEDEC/EMURB, quando coordenada por Mayumi.

O envolvimento de Mayumi com o ensino de arquitetura refletiu a explicitada posição crítica da arquiteta em sua atuação profissional. Deve ser analisado como parte do contexto de expansão do ensino superior, com a abertura de diversos cursos de Arquitetura, alguns desses caracterizados pela experimentação. Está entrelaçado, ainda, com questões que vinham sendo levantadas há algum tempo pelo campo cultural e social como as discussões sobre o papel social do arquiteto, a metodologia de ensino nos cursos de arquitetura e os objetivos do ensino superior em geral. Este foi um aspecto já constatado por Buitoni, no estudo da trajetória de ensino da arquiteta:

"O estudo da atividade docente de Mayumi é fundamental para entender a elaboração de sua postura crítica de projeto, porque as questões que ela enfrentava no ensino estavam diretamente vinculadas ao contexto social, político e econômico do país e à sua atuação profissional. A universidade apresenta-se como um espaço de reflexão sobre a atuação profissional do arquiteto, onde se oferece a oportunidade de troca de experiências e de elaboração de práticas alternativas de ensino e de projeto. " (BUITONI, 2009, p. 27)

O envolvimento com a UnB, ainda em um momento inicial da sua carreira e enquanto professora assistente, deve ser entendido no contexto do clima de otimismo com as novas possibilidades de ensino propostas na universidade. Conforme depoimento de Mayumi e Sérgio a Pinto (1989, p.143), tal otimismo foi rapidamente impactado pelo fechamento do curso a partir do golpe militar. Já os cursos de Santos e São José dos Campos, na década de 1970, se aproximam por seu caráter experimental e presença de preocupações políticas, além da busca por interação com camadas populares, em um contexto de repressão por parte do governo.

Por último, a passagem pelo curso de São Carlos, no fim da década de 1980 e início de 1990, reflete as questões que haviam sido levantadas nos cursos anteriores e está ligado ao momento de redemocratização do país. Na carreira profissional da arquiteta, está ligado à atuação na diretoria da CEDEC/EMURB, com produção de equipamentos 
públicos para a cidade de São Paulo, associado às novas concepções de governo democrático e às lutas populares que ganharam força com a abertura política.

No artigo Demandas internas: Mitos e impossibilidades reais nas universidades privadas e nas públicas, elaborado para o X Encontro Nacional Sobre Ensino de Arquitetura e V Congresso da Área (1991) e publicado posteriormente no livro Arquitetura e Educação, Mayumi questionava a "falsa democratização" do ensino universitário a partir da reforma universitária de 1968, iluminando o quadro de sucateamento das universidades públicas e criação de instituições privadas de baixa qualidade. Para ela, esse quadro crítico nos cursos de graduação trouxe diversas consequências para os cursos de Arquitetura: decorriam disto a despolitização e a formação fragmentada, atreladas a uma sobrecarga de horas de aulas ocupadas por disciplinas excessivamente específicas. Ela defendia, em oposição a isso, um ensino de Arquitetura mais amplo e aberto durante a graduação, com disciplinas que refletissem os conhecimentos básicos necessários para universitários e profissionais.

"Professores que repetem fórmulas projetuais conhecidas, seja porque comum no mercado imobiliário, seja porque adotadas por profissionais reconhecidos pelo mercado. E, neste caso, a preservação de mitos ou criação de novos faz parte do procedimento adotado pelos docentes, na medida em que os mitos não podem ou não devem ser discutidos. Desrespeitam-se os profissionais assim mitificados e desrespeita-se a formação do aluno, porque de ambos tira-se o essencial: o valor do seu trabalho criativo e inteligente". (LIMA, 1995, p. 62)

Fica claro, assim, a defesa constante de formas de ensino que superassem as fórmulas convencionais e suas limitações, como no exemplo da experiência da UnB, citado por Mayumi em diversos textos e entrevistas. Ao falar sobre o curso de São José dos Campos (LIMA In: PEDREIRA, 1986), esse posicionamento é reforçado e ela reafirmava a necessidade de uma formação mais ampla do arquiteto, não limitada somente ao campo disciplinar. Criticava, ainda, a despolitização nos cursos de Arquitetura, como mencionado acima, e a crença na "neutralidade do fazer profissional" (LIMA, 1995, p. 59), reforçando a formulação de um ponto de vista preciso a respeito da formação dos estudantes.

\section{Ensino em São Carlos, equipamentos públicos e o trabalho na Prefeitura de São Paulo}

Com base nas afirmações anteriores, torna-se mais fácil contextualizar o trabalho de Mayumi no CAU-EESC-USP. Seu envolvimento com o curso, recém-fundado, tem início em 1987 como professora da disciplina de projeto para alunos do terceiro ano. Havia um esforço na garantia de uma interdisciplinaridade, principalmente com a interação entre a área de projeto e a área de tecnologia, visto a grande importância dada pela arquiteta à escolha de técnicas construtivas condizentes com o edifício e com o local em que se inseria.

9 Sobre sua trajetória, veja-se: CERÁVOLO, Ana Lúcia Paulo de Camargo e Almeida: Arquitetura Total na trajetória de um arquiteto brasileiro. Dissertação (Mestrado) - Escola de Engenharia de São Carlos, Universidade de São Paulo, São Carlos, 2000.
O estudo e desenvolvimento da tecnologia construtiva já eram marcas presentes na EESC desde antes da idealização do curso de Arquitetura. O trabalho do arquiteto Paulo de Camargo e Almeida ${ }^{9}$, responsável pelo Mestrado em Industrialização das Construções fundado na escola, constituiu-se como referência entre as experiências brasileiras de pré-fabricação nos anos 1970. Contando com a contribuição da equipe de professores Dante Martinelli, João Bento Hanai e Frederich Schiel, o Laboratório de 
Estruturas da Universidade atuava no desenvolvimento da aplicação da técnica construtiva de elementos pré-moldados de argamassa armada (KOURY, 2007). O contato com essa pesquisa foi de grande importância para Mayumi, que posteriormente viria a utilizar a técnica em seu trabalho na Prefeitura de São Paulo.

Fundado em 1985, o curso de graduação em Arquitetura e Urbanismo do então departamento de Arquitetura e Planejamento da EESC-USP surgiu como consolidação de uma ideia antiga, uma vez que o curso de pós-graduação do departamento já existia desde 1971 e a implantação do curso de graduação já havia sido aprovada desde 1977. Segundo depoimento dos professores envolvidos com a sua estruturação - Agnaldo Farias, Carlos Martins, Gelson Almeida e Azael Camargo - no contexto dos anos 1980, as maiores dificuldades eram o desafio de integrar-se à nova realidade dos arquitetos que seriam formados, sem deixar de formar uma consciência social (MARINHO, 1986).

A formação do corpo docente foi efetivada de maneira particular e diversa do tipo de seleção contemporânea: a cada turma que ingressava no curso, composta de 30 alunos, novos professores eram incorporados, até a constituição de todos os períodos e formatura da primeira turma, em 1990. Nos concursos para admissão, os professores interessados deveriam enviar um projeto de trabalho para a disciplina de seu interesse, sendo selecionados pela maneira como pretendiam trabalhar os conteúdos e de que forma se inseriam no processo de formação. Este modo de operar refletia o desejo de formular um curso em um constante processo de construção que surgisse da síntese das experiências de ensino brasileiras das duas décadas anteriores.

Foi dessa forma que, em 1987, Mayumi foi incorporada ao quadro de professores. Uma reflexão geral das ideias inicialmente propostas por ela pode ser encontrada no documento referente ao primeiro programa da disciplina Projeto $V$, datado de fevereiro de 1987, depositado no seu acervo pessoal. A partir de outros documentos similares do acervo, é possível traçar um panorama geral dos conteúdos abordados, atividades propostas e questões discutidas pela disciplina nos seis anos em que Mayumi esteve ligada a ela e que serão analisados a seguir.

De 1987 até 1994, Mayumi ministrou as disciplinas de projeto do terceiro ano. Divididas entre dois semestres, as disciplinas de início denominadas como Projeto V e Projeto VI foram posteriormente unificadas sob o título Projeto III. Por meio de entrevista soubemos, também, de sua participação por um semestre na disciplina de projeto do primeiro ano,

10 Entrevista com o ex-aluno José Fabrício Ferreira. em $1992^{10}$. Adicionalmente, foi coordenadora da Área de Projeto, entre 1987 e 1988, e participou das seguintes comissões no Departamento de Planejamento e Arquitetura da EESC-USP: Comissão de vestibular; Comissão de pós-graduação, Comissão de implantação do curso de gradução; e Comissão de seleção de professores (LIMA, 1995).

A disciplina de Projeto do terceiro ano tinha como tema central o edifício público, abordado na perspectiva da relação entre os usuários e os agentes envolvidos em sua produção. As reflexões gerais das ementas reforçavam a dimensão dos edifícios públicos enquanto espaços destinados ao uso coletivo, devendo assim satisfazer as necessidades heterogêneas da população. O processo político de produção desses equipamentos era sempre enfatizado, uma vez que sua distribuição e características refletiam uma forma de organização social e estavam ligadas à interpretação do Estado e das classes dominantes sobre as necessidades das cidades e da população. 
11 Do documento Disciplina: Projeto V - SAP 335 / Ano de 1987, consultado no Acervo Mayumi Souza Lima do Centro Sérgio Buarque de Holanda.
Além disso, tratava da produção e distribuição dos equipamentos públicos e a forma como isso interferia na dinâmica espacial urbana. O equipamento público nunca era entendido por Mayumi como uma construção única, mas sim como parte de uma rede e, portanto, indissociável à sua articulação com os outros edifícios que a compõem.

O objetivo da disciplina era colocado como o de "iniciar o conhecimento sistemático dos processos individuais de projetação de edifícios, através de exercício práticos e análise dos métodos utilizados no seu desenvolvimento" ${ }^{11}$. Esses exercícios práticos se desenvolveram em torno do projeto de escolas, centros culturais e equipamentos de saúde, dentre outros, considerados em situação deficitária na cidade de São Carlos e adequados à proposta do curso no que dizia respeito à escala e ao programa. Um aspecto amplamente enfatizado nas ementas de disciplinas à que foi possível ter acesso é a interdisciplinaridade. A integração com a área de História era trabalhada a partir da análise da evolução histórica dos equipamentos e dos serviços prestados por eles, consolidando conceitos já vistos durante o processo de projeto.

A integração com a área de Tecnologia demandava um pouco mais de atenção. Mayumi demonstrava uma grande preocupação com a formação do conhecimento técnico dentro do ensino de arquitetura, defendendo sua aplicação como parte integrante do processo de projeto e não apenas como instrumento dissociado. Tal posição é evidenciada pelo documento manuscrito intitulado O Conhecimento de Ciência e Tecnologia na Formação do Arquiteto, encontrado em seu acervo pessoal:

"Quero dizer que as obras de arquitetura inovadoras não surgem do nada ou apenas da imaginação criadora do arquiteto, mas que sempre corre na angústia de resolver problemas de seu tempo. Nesse esforço ele lança mão de todos os conhecimentos de que dispõe, e embora nem sempre a totalidade de suas propostas possa ser técnical materialmente resolvida com os conhecimentos da época, ele consegue projetar com vistas ao futuro. "(LIMA, sem data, manuscrito encontrado no acervo Mayumi Souza Lima do Centro Sérgio Buarque de Holanda)

O título já torna evidente uma valorização do conhecimento técnico e de sua importância como processo de projeto e o texto mostra o seu valor, mesmo que as soluções propostas não possam ser viabilizadas pelo domínio científico e tecnológico disponível. Outra constatação importante é a adesão à ideia de que a produção arquitetônica de um determinado momento possa ser identificada como expressão cultural de sua época e das condições tecnológicas que a possibilitaram, ao mesmo tempo que é responsável pela exploração e avanço de tais condições.

A análise de obras a partir de sua experimentação técnica era utilizada como estratégia didática, de acordo com o trecho do mesmo manuscrito "passaremos ao longo dos arquitetos mais conhecidos e estudados da modernidade, porque a familiaridade aparente tira dos alunos a curiosidade que é o motivo forte para observar e perceber aspectos novos". Os exemplos abordados demonstravam a relação da arquitetura com o vidro e a luz, sempre condicionada pelo conhecimento técnico. Eram usados como exemplos desde projetos de Frank Lloyd Wright e Mies Van der Rohe, obras como o Glass Pavillion, de Bruno Taut, até as mais recentes Sydney Opera House, de Jorn Utzon, e projetos de Tadao Ando, evidenciando afinidades eletivas. 
Merece atenção especial o uso do exemplo das obras do arquiteto Kenzo Tange, devido à grande quantidade de transparências com imagens de diversos de seus projetos encontrada no acervo de Mayumi, revelando uma admiração especial e, talvez, um posicionamento a seguir. Há o apontamento dos diversos tipos de conhecimento trabalhados pelo arquiteto de acordo com cada projeto. A Residência do Arquiteto, de 1953, construída em madeira conforme a tradição japonesa, é contraposta ao Pavilhão Olímpico de Tokyo, de 1964, cujas curvas só foram possíveis devido ao uso de cabos tensionados. Os projetos se apresentam, assim, de forma muito distinta no que diz respeito ao resultado formal e às soluções construtivas, ainda que ambos apresentem características tanto modernas quanto da arquitetura tradicional japonesa e um enorme conhecimento técnico, uma enorme experimentação nas escolhas materiais e na articulação profunda entre forma e estrutura que tanto interessava a Mayumi.

Outro aspecto interessante em que se manifesta a importância dada por Mayumi ao conhecimento de técnicas construtivas como instrumento de ensino é relatado no livro Arquitetura e Educação. O uso de estruturas da natureza em comparação com o funcionamento de estruturas artificiais foi um recurso didático que ela fez presente durante os cursos de Santos, São José dos Campos e São Carlos, demonstrando a sua vontade de instigar nos alunos a curiosidade para a compreensão dos comportamentos estáticos.

O depoimento do professor Marcelo Tramontano do IAU-USP, que dividiu a disciplina de Projeto com Mayumi, mostra como era de grande importância na formação dos alunos o esforço para garantir discussões ligadas a materiais e técnicas construtivas e suas possibilidades. Esse esforço fica evidente, por exemplo, no documento referente a um exercício proposto na disciplina de Projeto VI, do segundo semestre de 1990. Com o título de "Espaço para habitação provisória de crianças alienígenas", tratava-se de uma atividade curta para iniciar a disciplina com o tensionamento do conhecimento prévio e das experiências dos alunos. Partia da proposição imaginária da queda de uma nave com crianças alienígenas em São Carlos. A partir do detalhamento de sua anatomia, acompanhado de um desenho cotado de uma dessas criaturas e de uma descrição de sua rotina, era proposta a elaboração de um projeto que pudesse ser construído em apenas 48 horas com o uso de chapas metálicas e de vidro de dimensões definidas. O desafio estava não apenas no ato de projetar uma situação desconhecida, mas também na melhor utilização técnica dos materiais propostos. No mesmo sentido, é possível citar também o projeto proposto como exercício principal para o segundo semestre de 1989, correspondente ao desenho de um sistema de componentes industrializados aplicado à construção dos equipamentos de uma rede de serviços de atendimento de saúde.

A interdisciplinaridade entre as áreas de projeto, linguagem e representação pode ser constatada no exercício realizado na disciplina de Projeto I do ano de 1992, denominado "A sociedade do Tubo". Conforme relatado pelo ex-aluno José Fabrício Ferreira, a proposta da atividade se baseava em um povo fictício que havia escapado de uma hecatombe nuclear, refugiando-se no subsolo, o chamado "Tubo", onde permaneceram refugiados durante muitos séculos, até que perceberam que o perigo havia terminado e que a Terra poderia ser reabitada. O exercício do semestre era desenhar todas as instâncias da vida dessa sociedade desde a casa, as roupas, até a cidade.

Outro ponto que merece atenção é a inserção de preocupações sociais nas discussões vinculadas às aulas de projeto. Exemplo disso é a proposição de exercícios como o 
projeto de um equipamento voltado para pessoas infectadas com o vírus HIV e um equipamento que possibilitasse o convívio entre idosos e crianças, relatados pelos colegas professores Fernando de Mello Franco e Marcelo Tramontano, respectivamente.

A estratégia de exercícios curtos ou seminários individuais que estimulassem a reflexão e percepção da complexidade envolvida no projeto de edifícios públicos era bastante utilizada como forma de iniciar a disciplina. No que diz respeito à metodologia das disciplinas, também é interessante apontar as aulas expositivas dadas através de palestras de arquitetos convidados, tendo como tema um projeto de sua autoria ou uma questão de relevância que estava sendo trabalhada pelos alunos. Como exemplo, pode ser citado o documento referente à disciplina de Projeto III do segundo semestre de 1993, em que constam no cronograma as seguintes palestras: arquiteto José Mário Nogueira, "convento dos padres" (referindo-se à obra Residência dos Padres Claretianos, Batatais, 1981-1983 que explorava habilmente as possibilidades dos tijolos como estrutura portante e cobertura); Eduardo Longo, "a casa bola" (projeto elaborado e construído entre 1972 e 1979 e marcante pelo experimentalismo, no período); Roberto Loeb, "o desenvolvimento de anteprojeto" (dizendo respeito a uma explicação sobre seu próprio processo e as etapas do projeto); e Ricardo Caruana, "arquitetura em madeira" (dando a oportunidade aos alunos de conhecerem mais um sistema construtivo).

Conforme depoimento dos arquitetos e professores Paulo Castral e Ana Lúcia Cerávolo, ex-alunos de Mayumi no curso de São Carlos, outra dimensão enfatizada por ela era a cobrança do detalhamento dos projetos, para além do plano preliminar. Em alguns momentos, era proposto o detalhamento dos esquemas de proteção solar ou do mobiliário do edifício, através de uma integração com a disciplina "Desenho do Objeto", ministrada pelo professor Jorge Caron. O papel exercido por Mayumi no ensino da elaboração de programas arquitetônicos também foi mencionado por eles, a atenção dada para a correção dos exercícios e para o retorno das avaliações. A questão também foi enfatizada pelo professor Marcelo Tramontano, ao relatar os longos períodos dedicados à correção, rigorosa no que dizia respeito ao domínio construtivo demonstrado pelos alunos.

O envolvimento de Mayumi na EESC-USP não se limitou, no entanto, apenas à disciplina de projeto. Durante o período que esteve em São Carlos, realizou diversas palestras e exposições didáticas na USP e na UFSCar, marcando a contribuição não apenas para o curso de Arquitetura e Urbanismo, mas para a comunidade universitária da cidade, baseada nessas duas universidades. Relatadas em seu currículo, tais atividades apresentavam temas ligados à produção de equipamentos coletivos e industrialização da produção. Outra contribuição muito importante para comunidade acadêmica ocorreu com a doação dos livros pertencentes a Mayumi e Sérgio Souza Lima por seu filho, Mário, à biblioteca da EESC-USP. Ao relatar esse fato, o professor Carlos Roberto Monteiro de Andrade, com quem Mayumi dividia sua sala no Departamento de Arquitetura e Planejamento, ressaltou sua importância, com ganho de uma grande quantidade de livros da área de humanidades.

Para além de sua atuação como professora, Mayumi tinha participação ativa nas plenárias e discussões políticas no curso de Arquitetura. Segundo depoimento do professor Renato Anelli, com quem dividiu a disciplina de Projeto, seus discursos em tais ocasiões exerciam um papel importante no engajamento dos alunos. Um exemplo disso, relatado pelo 
12 Agradecemos à servidora técnico-administrativa Debora Martinez pelas informações, provenientes da pesquisa nas atas de comissões do Departamento de Arquitetura e Planejamento.

13 Ferreira ainda comenta o quanto os alunos eram entusiasmados com sua presença em sala de aula e como os veteranos os informavam de que "aquela delicada senhora era uma das gigantes da arquitetura brasileira, perseguida e torturada pela ditadura militar".

Figura 2: Mayumi Souza Lima com alunos do primeiro ano do curso de São Carlos, 1992, em ocasião de homenagem a ela. Fonte: Fotógrafo não identificado. Acervo Arquiteto Gustavo Castro e Lima. professor, foi de uma aula memorável em 1990, em que Mayumi relatava a experiência de desenvolvimento de escolas pelo CEDEC. Partia do relato de sua visão das crianças na periferia e de como já vivenciavam a desespacialização na fase da infância, por frequentarem espaços não-qualificados e deixarem de circular na cidade, onde eram vistas como ameaça. Surgia, assim, a necessidade de criar uma identificação com a escola, com o bairro e com os próprios alunos. Esse relato exerceu grande impacto nos estudantes de arquitetura.

A presença de Mayumi em reuniões de órgãos e conselhos do departamento está documentada e pôde ser resgatada através do Projeto Memória do IAU-USP. Dentre as muitas contribuições, ela apresentou um possível programa de pesquisa para o departamento e partiu dela o pedido de manter os ateliês abertos para além do horário das aulas e aos fins de semana, atendendo demandas dos estudantes, com a justificativa de estratégia pedagógica da sequência de projeto e do curso ${ }^{12}$.

Os depoimentos dos ex-alunos revela uma postura firme, mas carinhosa com os alunos. A fotografia (figura 2) que apresenta Mayumi entre os estudantes é o registro de uma homenagem dos alunos do primeiro ano, no primeiro semestre de 1992, que retribuíam um gesto generoso da professora. Como apresentado por depoimento de José Fabrício Ferreira, em viagem didática guiada por Mayumi a São Paulo, após visita à canteiros de obras, edifícios e museus, foi feita uma pausa para um lanche e confraternização em um bar, antes do retorno para São Carlos. Diante de um mal entendido que gerou uma conta caríssima para aqueles estudantes, Mayumi discretamente se levantou e assinou um cheque quitando-a. Os estudantes tentaram descobrir o valor total para ao menos acertar posteriormente, algo que ela não aceitou. Para retribuir o ato, tiveram, então, a ideia de presenteá-la com um vaso de orquídeas, como testemunha a foto ${ }^{13}$.

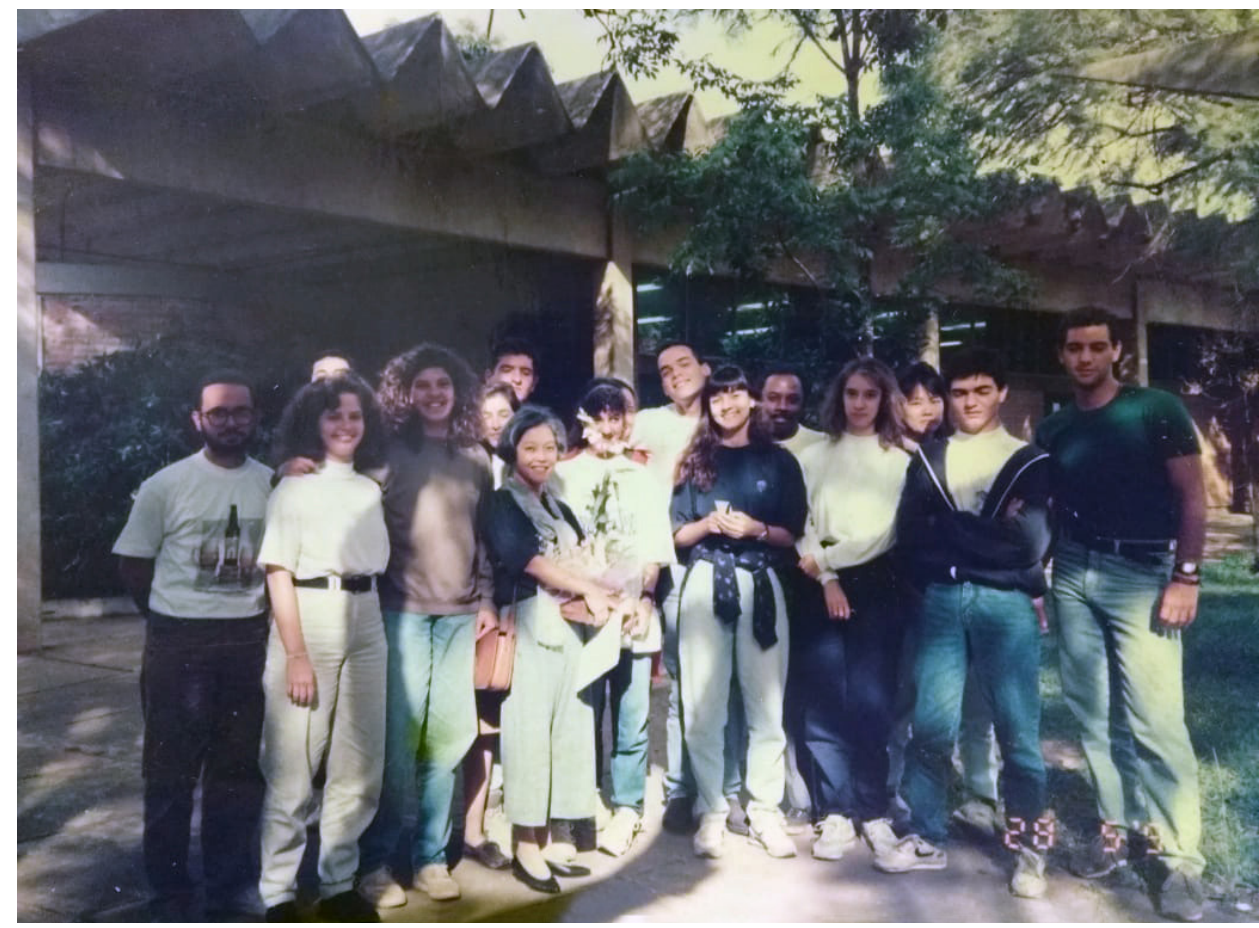




\section{arquitetura $\boldsymbol{e}$ equipamentos sociais}
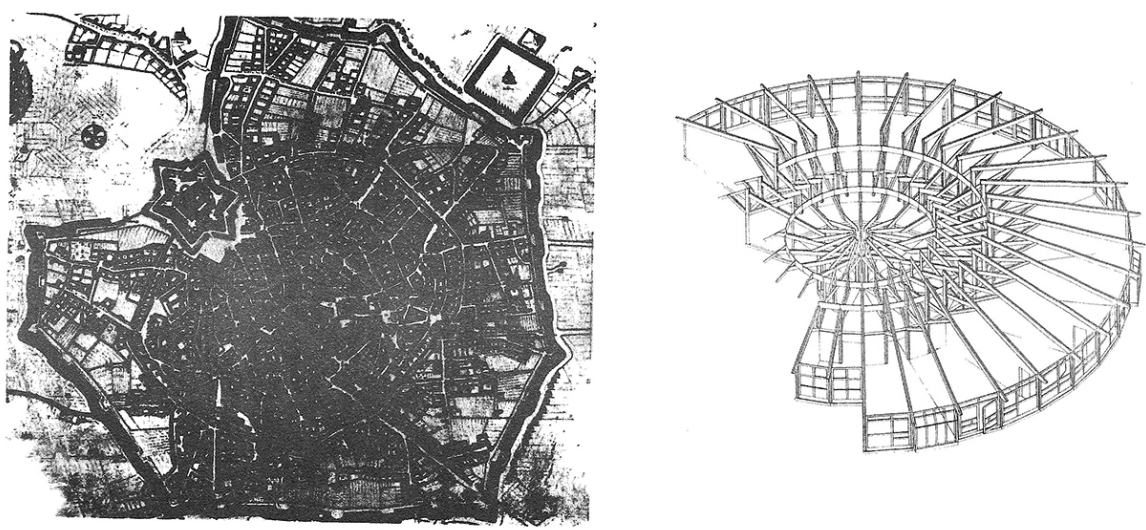

Figura 3: Capa da apostila Equipamentos Coletivos e Públicos: Educação e Saúde - anotações de aula, produzida por Mayumi em 1992 como material didático de apoio à disciplina de Projeto. Fonte: Acervo da Biblioteca Central da EESC-USP.

${ }^{14}$ Conforme depoimento para a matéria História viva do IAU: Fátima Mininel. São Carlos, julho de 2019. Disponível em $<$ http://www.iau.usp.br/index. php?option=com_content\&view $=$ article\&id=854: historiaviva-do-iau-fatima-mininel\&cati$d=36 \& \mid$ temid $=185>$. Acesso em: 08/06/2020.
Essa postura afetuosa se estendia aos servidores técnico-administrativos, conforme depoimento de Fátima Mininel, chefe do Serviço de Expediente e Protocolo do IAU ${ }^{14}$. Em relação aos colegas professores, é unânime para Anelli, Tramontano e Fernando de Mello Franco (então seu colega na disciplina de Projeto) o aprendizado possibilitado pela convivência com ela.

O principal material didático produzido por Mayumi para o curso de Arquitetura de São Carlos foi a apostila Equipamentos Coletivos e Públicos: Educação e Saúde - anotações de aula, publicada em 1992 pela gráfica da EESC-USP (figura 3). A apostila relata a progressão histórica dos edifícios coletivos ligados à educação e à saúde, partindo do princípio de que suas características, distribuição e finalidade estavam intrinsicamente ligadas aos padrões culturais, tecnológicos e econômicos das sociedades em que se inseriam. É importante notar a afirmação de que tais equipamentos eram moldados para atender as demandas das classes dominantes, desde seu surgimento, situação que teve uma permanência na história. Mais do que um comentário meramente arquitetônico, a apostila se baseava em uma análise política, com crítica aos espaços projetados sem priorizar os usuários de tais equipamentos e a defesa da produção de uma rede de equipamentos de qualidade.

Como já apresentado, paralelamente ao trabalho como professora em São Carlos, Mayumi atuou em órgãos da Prefeitura Municipal de São Paulo durante a gestão de Luiza Erundina. De 1990 a 1992, foi responsável pela coordenação do CEDEC, setor de pesquisa e de produção industrial de equipamentos dentro da Empresa Municipal 
de Urbanização (EMURB). O CEDEC era responsável por uma fábrica de elementos pré-moldados de argamassa armada para servir à construção de equipamentos públicos e mobiliário urbano, com implantação coordenada por Mayumi, conforme projeto fornecido por Lelé e assessoria de engenheiros da EESC-USP (BUITONI, 2009).

Uma parte da apostila é dedicada ao projeto da EMEI Vila Nova Curuçá, coordenado por Mayumi dentro do CEDEC/EMURB, com análise da própria arquiteta sobre o projeto e os direcionamentos que foram considerados importantes em seu desenvolvimento (figuras 4 e 5). De acordo com a apostila, quatro elementos básicos eram considerados pelo CEDEC para dar início à concepção de espaços educacionais: a criança; a proposta pedagógica; as condições do terreno; e o entorno da área onde a escola seria inserida, indicando com isso uma os fundamentos considerados importantes para pensar o projeto. Além disso, era de grande importância um desenho que possibilitasse a integração da escola com o bairro permitindo o uso de alguns de seus espaços como playgrounds e quadras de esporte pela comunidade.

Outra forma de assegurar essa identificação da comunidade e dos alunos com a escola se dava por meio dos elementos de comunicação visual (figura 6). Incluía-se nisso a criação de um logotipo para cada escola, ligado à origem do nome do bairro onde a escola se localizava. Esses logotipos eram colocados em lugares como caixas d'água e entradas, para permitir sua identificação à distância. As entradas deveriam ser, assim, facilmente reconhecíveis, algo que era possibilitado pela colocação de abrigos pré-fabricados.

A questão da comunicação visual também aparece nos trabalhos de iniciação científica orientados por Mayumi na EESC-USP. Foram encontrados em seu acervo pessoal uma série de projetos e relatórios de pesquisa, datados de 1989 a 1991, que têm como principal foco o diagnóstico das escolas públicas com relação aos elementos de comunicação visual e a investigação da apreensão do espaço escolar pelas crianças da rede pública. Sob o título comum de Arquitetura dos espaços destinados à educação das crianças e dos jovens em São Paulo, as pesquisas incluíam registros fotográficos e fichas de elaboração e eram financiadas pelo Conselho Nacional de Desenvolvimento Científico

15 Documento Relatório Pesquisa $1^{\circ}$ Semestre 1989 - Arquitetura dos Espaços destinados à Educação de crianças e de jovens da rede escolar de São Paulo, consultado no Acervo Mayumi Souza Lima do Centro Sérgio Buarque de Holanda. e Tecnológico (CNPq). De acordo com relatório ${ }^{15}$ enviado ao órgão, a iniciativa tinha como objetivo não apenas identificar as carências das escolas analisadas, mas também propor e testar novas soluções para a comunicação visual dos espaços educativos, trazendo recomendações para futuros projetos (BUITONI, 2009).

Pode-se concluir, portanto, que o trabalho de Mayumi no CEDEC/EMURB foi de grande importância para sua atividade docente em São Carlos. Para além da concomitância entre as duas atividades, é possível apontar a similaridades dos temas desenvolvidos nas aulas e os projetos realizados pela companhia. O projeto de equipamentos como escolas, postos de saúde, centros de lazer e mobiliário urbano, dentre diversas outros desenvolvidos pelo CEDEC, merecem atenção por seu caráter público e social. Além disso, a escolha da argamassa armada como sistema construtivo pré-fabricado permitiu uma maior agilidade e barateamento das obras, essencial se observada a quantidade de equipamentos produzidos durante dois anos pela equipe.

O tema da pré-fabricação foi levado para o curso de Arquitetura da EESC-USP na disciplina de projeto do terceiro ano por Mayumi e o professor Kristian Schiel, devido, 
Escola Municipal de Ensino Infantil, de Vila Nova Curuçá, construida em 1992 para 600 crianças em dois grupos de 300 , destinada às crianças do bairro de mesmo nome, na periteria de Săo Paulo, ocupado por populaçăo de baixa renda. Projeto elaborado pela equipe do Centro de Desenvolvinento de Equipamentos Comunitarios CEOEC/EMURB - em sistema pré-fabricado de argamass armada. O projeto leva em conta a economia de tempo e cusio, a imexistencia de áreas e de equipamentos publicos n regiāo.
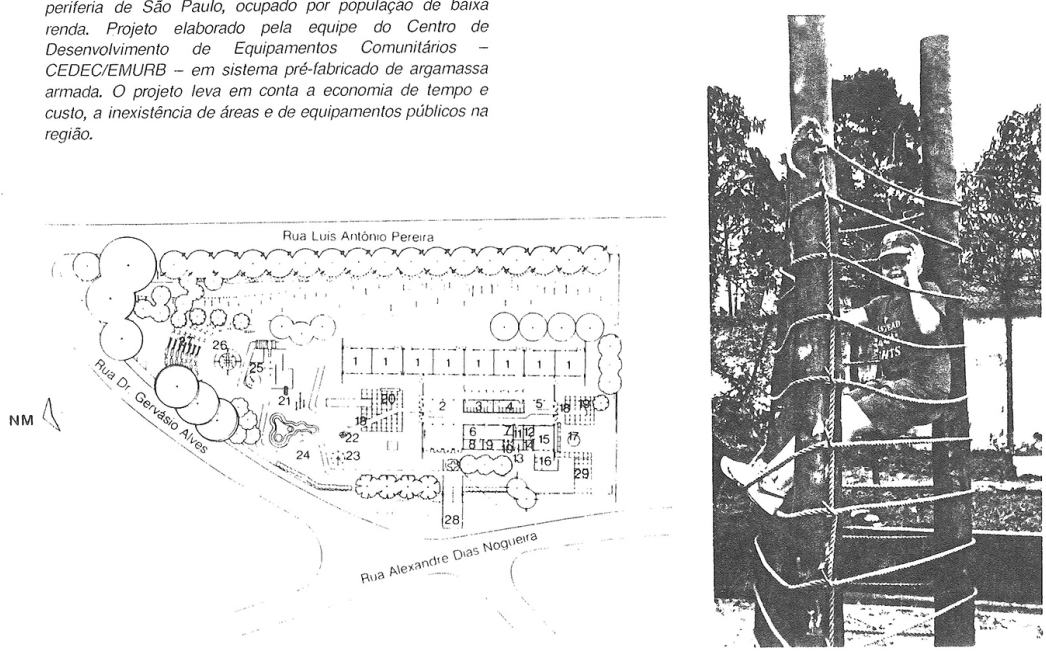

Figuras 4 e 5: Páginas da apostila Equipamentos Coletivos e Públicos: Educação e Saúde anotações de aula dedicadas ao projeto da EMEI Vila Nova Curuçá, CEDEC/EMURB, 1992. Fonte: Acervo da Biblioteca Central da EESC-USP.
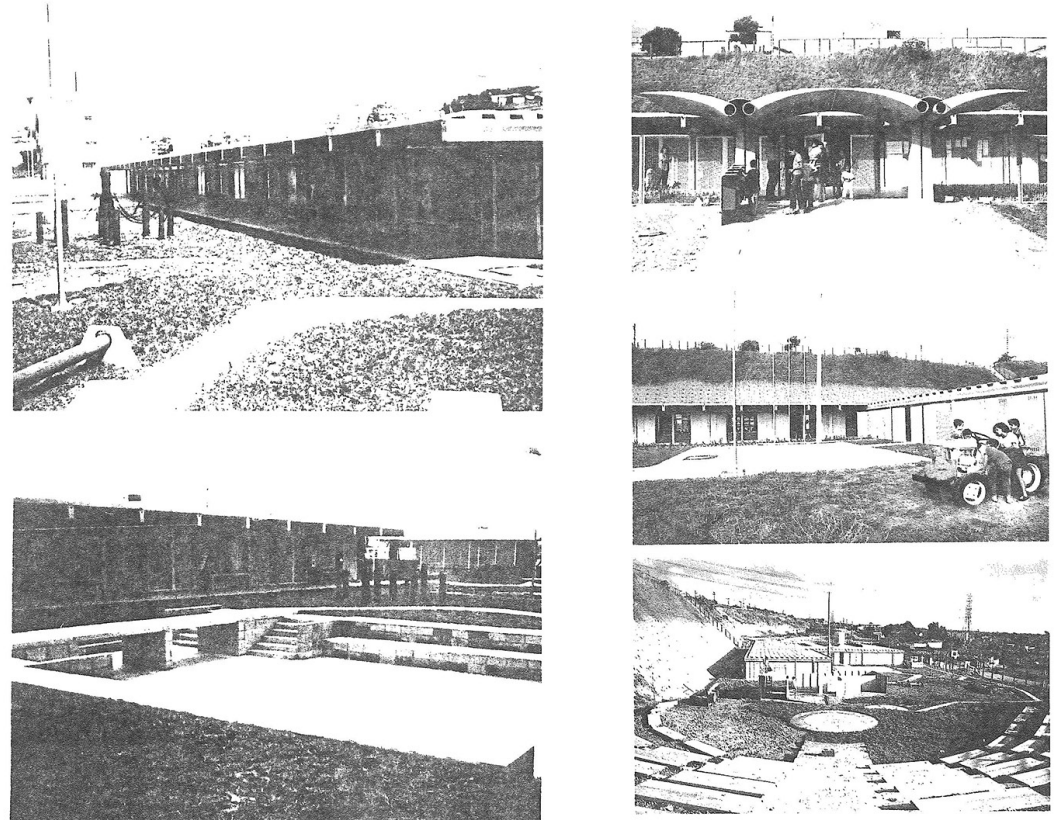


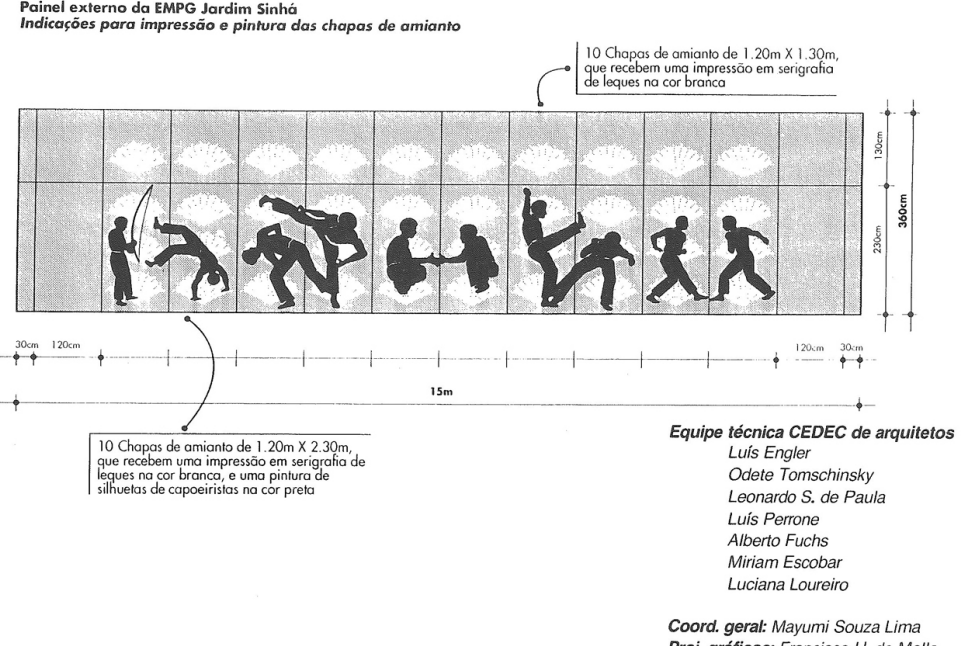

Figura 6: Painel externo da EMPG Jardim Sinhá, exemplo da comunicação visual nas escolas projetadas pela equipe do CEDEC/ EMURB na apostila Equipamentos Coletivos e Públicos: Educação e Saúde - anotações de aula. Fonte: Acervo da Biblioteca Central da EESC-USP. em parte, à experiência que ambos haviam tido na área, incluindo o trabalho com Lelé em Brasília. Mais do que uma questão construtiva, é possível perceber os debates envolvidos na escolha do método. Em um contexto de necessidade de expansão e capacitação da rede de equipamentos públicos, tornava-se desafiador que tal ampliação não fosse realizada com diminuição da qualidade dos projetos. A rapidez e os baixos custos trazidos pelo uso de sistemas produtivos em massa, com seus elementos industrializados e padronizados, não deveria refletir numa padronização arquitetônica como forma de suprir a demanda a qualquer custo. Tornava-se necessário, assim, combinar a produção em grande escala com projetos arquitetônicos únicos e voltados para os usuários e desenvolvidos caso a caso. O trabalho de Mayumi no CEDEC/EMURB e o que ela buscava ensinar no curso de São Carlos demonstram exemplos de que essas duas coisas não são necessariamente excludentes.

Durante o período em que trabalhou no CEDEC, Mayumi precisou reduzir suas atividades no curso, indo à São Carlos apenas durante um dia na semana, para as aulas de projeto. Ela não foi a única professora dali a trabalhar na Prefeitura de São Paulo durante a gestão Erundina: o professor da área de Teoria e História, Nabil Bonduki, também se afastou para poder se dedicar a cargos ligados à área de habitação. Sobre a atuação de Mayumi na Prefeitura de São Paulo, ele escreveu: "Este trabalho recoloca, pois, uma velha, mas ainda atual, questão posta pelos pioneiros do movimento moderno: a importância de se atender com qualidade às reais necessidades de espaço de toda a sociedade, rompendo a subserviência da arquitetura a uma parcela privilegiada." (BONDUKI, 1996, s.p.) 


\section{Conclusão: a ainda atual função social do arquiteto e o ensino como formação técnica e política}

A pesquisa permitiu uma maior compreensão da figura de Mayumi Souza Lima, ainda que dada a dificuldade do resgate de sua memória a partir de documentos e entrevistas, fontes que por vezes se mostram incompletas. O estudo de sua atividade docente não pôde ser dissociado de aspectos de sua formação e atuação profissional, bem como do contexto social e político em que se inseriu. Como resultado, tornou-se possível a construção de um perfil da figura de Mayumi no qual o seu caráter indissociavelmente político aparece sempre associado a uma postura ética muito forte. Conclui-se, por fim, que a contribuição de Mayumi para o curso de arquitetura e urbanismo da EESC-USP, ainda em seus momentos iniciais, foi de grande importância para sua estruturação e para o aprendizado daqueles que com ela conviveram, seja como alunos ou como colegas de profissão.

A contribuição de Mayumi para o IAU-USP pode ser identificada na preocupação com uma formação dos estudantes para além de arquitetos, mas como dotados de uma consciência social. Se em sua atuação em órgãos ligados ao Estado Mayumi fez o possível para garantir uma arquitetura de dimensão pública, de qualidade e voltada para a população, enquanto professora buscou transmitir essa orientação aos alunos. A docência de Mayumi em São Carlos deixou esta marca e mostra a atualidade da reflexão trazida pela arquitetura moderna a respeito do papel social do arquiteto e da sua colaboração para resolver os problemas da sociedade brasileira.

Outro aspecto em que a herança de Mayumi na escola ainda pode ser reconhecida é na relação entre arquitetura e tecnologia. Se o tema da pré-fabricação e a busca por soluções construtivas inovadoras se torna evidente em sua trajetória desde a colaboração com Lelé em Brasília à coordenação da fábrica do CEDEC/EMURB, também a análise dos escritos didáticos de Mayumi permitiu identificar a valorização do conhecimento técnico e de sua importância como processo de projeto. Exemplos da permanência dessa visão no curso podem ser apontados tanto na ênfase ainda dada ao projeto de equipamentos em rede no terceiro ano, quanto no esforço por interdisciplinaridade entre as disciplinas da área de projeto e de tecnologia construtiva.

A experiência docente de Mayumi em São Carlos coroa uma trajetória e reflete o impacto dos conhecimentos trazidos desde a docência na UNB e dos trabalhos ali desenvolvidos com a pré-fabricação, envolvendo interlocutores culturais como o já citado Lelé, mas, também, em seguida, Sérgio Ferro, Flávio Império e Rodrigo Lefévre, constituindo um grupo de arquitetos formados nas promessas modernas, capazes de construir críticas a elas, sem negar sua herança, a partir da reflexão profunda sobre a arquitetura e sua forma de produção.

Este aspecto se entrelaçou com a atividade prévia de pesquisas sobre pré-fabricação já realizadas em São Carlos por Paulo de Camargo, e, em específico na aplicação da argamassa armada com Martinelli, Hanai e Frederich Schiel. Elas deram insumos para o trabalho de Mayumi na Prefeitura de São Paulo e voltaram para o ensino, como em um jogo de espelhos, nas disciplinas que a arquiteta ministrava, contando ainda com a participação do professor Kristian Schiel. A atuação no CEDEC/EMURB também trouxe questões que seriam por ela desenvolvidas nas aulas de projeto e ela entrelaçou pesquisas desenvolvidas na escola a esse trabalho na Prefeitura. 
Tudo isso demonstra como atuação na administração pública da cidade de São Paulo e o trabalhou como docente e pesquisadora em São Carlos apresentaram trocas mútuas. Assim, acredita-se comprovar que sua atividade docente em São Carlos e o contato com seus interlocutores ajudou a afinar sua própria visão de arquitetura.

Para além do resgate da memória de Mayumi e do curso, foi possível estabelecer através de sua figura uma reflexão geral sobre arquitetura e ensino enquanto processos políticos de construção do mundo. Sua maior contribuição pode ser apontada, assim, como a luta por uma transformação social dentro e fora do campo da arquitetura.

\section{Referências bibliográficas}

ALIAGA FUENTES, Maribel. Mayumi e Sérgio Souza Lima: os blocos residências da Vila São Miguel. In: X SEMINÁRIO DOCOMOMO BRASIL ARQUITETURA MODERNA E INTERNACIONAL: conexões brutalistas 1955-75, 2013, Curitiba. Anais [...]. Porto Alegre: PROPAR/ UFRGS, 2013.

ALIAGA FUENTES, Maribel. Três pioneiras no cerrado. In: Fernando Serapião, Catherine Otondo (org.) Onde estão as mulheres arquitetas?. São Paulo: Monolito, 2017, p. 80-82.

Os primeiros mestrandos da FAU-UnB: de um passado que não se construiu. Tese (Doutorado)- Faculdade de Arquitetura e Urbanismo, Universidade de Brasília, Brasília, 2017.

BASTOS, Maria Alice Junqueira; ZEIN, Ruth Verde. Brasil: Arquiteturas após 1950. São Paulo: Perspectiva, 2011.

BONDUKI, Nabil Georges. Arquitetura para educar. Folha de São Paulo. São Paulo, março de 1996. Disponível em <http://www1.folha.uol.com.br/fsp/1996/3/08/caderno_especial/16. html>. Acesso em: 29/11/2019.

BUITONI, Cássia Schroeder. Mayumi Watanabe Souza Lima: a construção do espaço para a educação. Dissertação (Mestrado) - Faculdade de Arquitetura e Urbanismo, Universidade de São Paulo, São Paulo, 2009.

CEDEC/EMURB. Caderno 1: Centro de Desenvolvimento de Equipamentos Urbanos e Comunitários; Caderno 2: Canalização de córregos; Caderno 3: Espaços Educacionais: EMEl e EMPG; Caderno 4: Mobiliário Urbano. São Paulo: Emurb, 1991-1992.

CERÁVOlO, Ana Lúcia Paulo de Camargo e Almeida: Arquitetura Total na trajetória de um arquiteto brasileiro. Dissertação (Mestrado) - Escola de Engenharia de São Carlos, Universidade de São Paulo, São Carlos, 2000.

COMISSÃO DA VERDADE DA UNIVERSIDADE DE SÃO PAULO. Relatório final volume 5: Faculdade de Arquitetura e Urbanismo. Universidade de São Paulo, São Paulo, 2018. Disponível em <https://drive.google.com/drive/folders/1J73t6qk0XnXX2E-yPrRQYlmohSxRO9v9>. Acesso em 18 setembro 2020.

KOURY, Ana Paula. Arquitetura construtiva: Proposições para a produção da arquitetura no Brasil (1960-1970). Revista Projeto História, São Paulo, n.34, p. 189-203, jun. 2007.

LEFÈVRE, Rodrigo. Notas de um estudo sobre os objetivos do ensino de arquitetura e meios para atingi-los em trabalho de projeto. São Paulo: (mimeo) FAUUSP, 1978.

LIMA, Mayumi Watanabe de Souza. Entrevista. In: PEDREIRA, Lívia Álvares. Espaço da utopia. Revista Arquitetura e Urbanismo. São Paulo, n. 5, abr. 1986.

(coord). Espaços educativos - uso e construção. Brasília: MEC/CEDATE, 1988.

A Cidade e a Criança. São Paulo: Nobel, 1989. 
LIMA, Mayumi Watanabe de Souza. A Contribuição do Cedec/Emurb à Cidade. Revista Construção São Paulo, São Paulo, n. 2345, p. 12-3, 1993.

Equipamentos Coletivos e Públicos: Educação e Saúde - anotações de aula. Apostila. São Carlos: EESC-USP, 1992.

Arquitetura e Educação. São Paulo: Studio Nobel, 1995.

Escolha de material técnico e sistemas construtivos destinados à produção de habitação popular e de condições de habitablidade. Pós - Revista do Programa de Pós-Graduação em Arquitetura e Urbanismo da FAU-USP. Universidade de São Paulo, Faculdade de Arquitetura e Urbanismo, n.12, p. 118-130, 2002.

LIMA, Mayumi Watanabe de Souza; LIMA, Sérgio de Souza. Entrevista. In: PINTO, Gelson de Almeida. Prática do projeto no ensino de arquitetura: investigação sobre algumas experiências - São Paulo - 1958/1985. São Carlos: EESC-USP, 1989.

MENEGOZZO, Carlos Henrique Metidieri [org.]. Centro Sérgio Buarque de Holanda: Guia do acervo. São Paulo: Editora Fundação Perseu Abramo, 2009.

MARINHO, Gabriela. Momento da razão. Revista Arquitetura e Urbanismo. São Paulo, n. 5, Abril de 1986.

PINTO, Gelson de Almeida. Prática do projeto no ensino de arquitetura: investigação sobre algumas experiências - São Paulo - 1958/1985. São Carlos: EESC-USP, 1989.

PRONSATO, Sylvia Adriana Dobry. Para quem e com quem: Ensino de Arquitetura e Urbanismo. Tese (Doutorado) - Faculdade de arquitetura e Urbanismo, Universidade de São Paulo, São Paulo, 2008.

SEGAWA, Hugo. Arquiteturas no Brasil 1900-1990. São Paulo: Editora da Universidade de São Paulo, 1997.

SILVA, Joana Mello de Carvalho e. Arquitetura e política. In: Fernando Serapião, Catherine Otondo (org.) Onde estão as mulheres arquitetas?. São Paulo: Monolito, 2017, p. 87-90. 